\section{Impact of Ultraviolet-blocking Plastic Films on Insect Vectors of Virus Diseases Infesting Crisp Lettuce}

\author{
Beatriz M. Díaz \\ Departamento de Protección Vegetal, Instituto de Ciencias Agrarias, Centro de \\ Ciencias Medioambientales-CSIC, C/Serrano 115 dpdo., Madrid 28006, Spain
}

\author{
Ricardo Biurrún \\ Instituto Técnico de Gestión Agrícola, S.A. Ctra. El Sadar s/n, Edificio El \\ Sario, Pamplona 31006, Spain
}

\begin{abstract}
Aránzazu Moreno, Miguel Nebreda, and Alberto Fereres ${ }^{1}$
Departamento de Protección Vegetal, Instituto de Ciencias Agrarias, Centro de Ciencias Medioambientales-CSIC, C/Serrano 115 dpdo., Madrid 28006, Spain
\end{abstract}

Additional index words. Lactuca sativa, UV-blocking film, photoselective barrier, aphids, thrips, whiteflies, virus

\begin{abstract}
Ultraviolet (UV)-absorbing plastic films are being used as a photoselective barrier to control insect vectors and associated virus diseases in different horticultural crops. A 2-year experiment was carried out in northeastern Spain (Navarra) to evaluate the impact of a UV-blocking film (AD-IR AV) on the population density of insect pests and the spread of insect-transmitted virus diseases associated with head lettuce [Lactuca sativa (L.)]. Results showed that the UV-absorbing plastic film did not loose its ability to filter UV radiation after three lettuce crop cycles (14 months). The $\mathrm{UV}$-absorbing plastic film was effective in reducing the abundance and in delaying the colonization of lettuce by aphids [Macrosiphum euphorbiae (Thomas) and Acyrthosiphum lactucae (Passerini)]. Asignificant increase in the percentage of marketable plants was achieved under $\mathrm{UV}$-absorbing films due to a reduction in the number of plants infested by aphids and by insect-transmitted virus diseases (mainly potyviruses). Also the $\mathrm{UV}$-absorbing plastic films were effective in reducing the population density of Frankliniella occidentalis (Pergande) and the spread of tomato spotted wilt virus (TSWV) as well as the population density of the lepidopteran pest, Autographa gamma (L.), a common pest of lettuce in Spain. However, no effective control of the greenhouse whitefly Trialeurodes vaporariorum (Westwood) was achieved. The results showed that $U V$-absorbing plastic films are a very promising tool to protect greenhouse lettuce from the main pests and insect-transmitted virus diseases occurring in northeastern Spain.
\end{abstract}

Lettuce [Lactuca sativa (L.)] grown under protected environments is very susceptible to heavy infestations of insect pests and consequently to the spread of insect-transmitted virus diseases. This threat has adverse ecological consequences because of the large amount of pesticides that are currently being used to protect lettuce from insect pests. Also, pesticide residues are a major concern to consumers because lettuce is consumed as a fresh vegetable without any kind of processing.

Among insect control methods, physical barriers continue to play a significant supporting role today and are likely to have a significant role in the integrated pest management (IPM) programs of the future (Boiteau, 2002). The use of UV-blocking cladding materials can play a part in IPM programs for crop protection in greenhouses (Antignus and Ben-Yakir, 2004) because they are compatible with the use of

Received for publication 30 Jan. 2005. Accepted for publication 9 Mar. 2006. We thank the Spanish Ministry of Science and Technology (Research Grant, no.:AGL:2000-2006 andAGL-2003-07532-C03-01 for funding this work.

${ }^{1}$ To whom reprint requests should be addressed. e-mail afereres@ccma.csic.es. biopesticides (Costa et al., 2001) and natural enemies (Chyzik et al., 2003).

The UV-blocking films act as a photoselective barrier that modifies the greenhouse environment and disrupts the normal insect behavior so as to discourage pest activity. As a consequence few insects invade these structures and the opportunity for virus transmission is reduced (Raviv and Antignus, 2004). Although most of the plastic films contain UV-absorbing properties to extend the life of the material, only a few plastics are available on the market to block over $95 \%$ of UV light transmission in the range between 200 to $380 \mathrm{~nm}$ while allowing $80 \%$ transmission of photosynthetic active radiation (PAR) (Antignus et al., 1996).

The blockage of UV radiation interferes with insect vision, navigation, orientation and feeding behavior causing a significant reduction in population density and dispersion of insect pests such as aphids, thrips and whiteflies (Antignus et al., 1996, 1998, 2001; Costa and Robb, 1999; Costa et al., 2002; Mutwiwa et al., 2005). Chyzik et al. (2003) observed that UV-absorbing films also acted as an inhibitor of Myzus persicae (Schulzer) propagation and dispersal by reducing its flight activity.
UV-absorbing films are effective in reducing insect transmitted viral diseases (Antignus et al., 1996). A significant reduction in virus spread has been observed in Bemisia-transmitted viruses such as tomato yellow leaf curl virus (TYLCV) and cucurbit yellow stunting disorder virus (CYSDV) in tomato and cucumber crops, respectively (Antignus, 2000).

This significant decrease in the spread of these viruses has been attributed to the impairment of whiteflies to fly and disperse in the absence of UV-light (Antignus, 2000; Antignus et al., 2001).

Most of the information related to the effects of UV-light absorbing plastic films on insect populations and virus spread has concentrated in tomato and cucurbits. To our knowledge, there is no information on the impact of UVabsorbing plastics on insect pests and virus diseases commonly found in lettuce crops grown under greenhouse environments.

The aim of this work was to study the population dynamics of insect pests and the spread of insect-transmitted viruses in a lettuce crop grown in a greenhouse covered by a UV-light absorbing film. Also, the impact of UV-absorbing films on the growth and yield of lettuce as well as the mean temperature inside the greenhouse was compared to that obtained when using standard polyethylene films.

\section{Materials and Methods}

Experimental design. The experiments were conducted on a crisphead lettuce crop grown under greenhouse conditions at Sartaguda (latitude $42^{\circ} 21^{\prime} \mathrm{N}$, longitude $1^{\circ} 38^{\prime} \mathrm{W}$, altitude $310 \mathrm{~m}$ ), Navarra (Spain), and were replicated three times: Fall 2002, Spring 2003, and Fall 2003. Two commercial greenhouses, walk-in tunnel type, measuring $40 \mathrm{~m}$ long $\times 9 \mathrm{~m}$ wide $\times 2$ m high were used to compare the two types of plastic film covers. Both greenhouses were separated with $50 \mathrm{~m}$ between each other, had the same orientation and were identical except for the type of plastic film cover to be tested.

Each greenhouse had unscreened small openings at each side of the tunnel and on the roof to facilitate ventilation. These openings allowed unfiltered light to enter the greenhouse structure. Doors were occasionally covered with nets to avoid wind damage to lettuce plants. A black plastic mulch covering the soil was used for weed control and to increase soil temperature. Air temperature was recorded continuously during the whole crop growth cycle by a thermograph (model Standard MX 173; Robert E. White Instruments, Boston, Mass.) placed in the middle of each of the two tunnels.

Plastic films tested. Two types of plastic films were used for comparison: a UV-absorbing film (AD-IR AV clear manufactured by Ginegar Plastic Products Co., Ginegar, Israel) and a non-UV absorbing film (control) standard polyethylene plastic film commonly used at the experimental site and called Astrolux (Hyplast Ltd., Hogstraten, Belgium). Both types of plastic films had similar physical properties (thickness, anti-drip, anti-dust, thermicity, visible light transmission and diffusion) ex- 
cept for their ability for UV-blockage. The light transmitted for both plastic types was measured experimentally at the beginning and at the end of the three lettuce growing seasons. The amount of UV ( 250 to $400 \mathrm{~nm}$ ) and visible light (400 to $700 \mathrm{~nm}$ ) transmitted by both plastic types was measured using a spectroradiometer (models UVM and BQM, respectively, Spectrum Technologies, Apogee Instruments, Logan, Utah). Measurements were taken inside and outside the plastic tunnels by placing the sensor perpendicularly to open sunlight in a sunny day at 12:00 HR with an outside air temperature of $15{ }^{\circ} \mathrm{C}$.

Cropping practices. The impact of the UV-blocking film (AD-IR AV) on insect pests and diseases was evaluated on three lettucegrowing cycles in two different seasons, Fall and Spring. Two growing cycles were studied in Fall 2002 (9 Sept. to 7 Nov.) and Fall 2003 (12 Sept. to 29 Oct.) and one in Spring 2003 (28 Mar. to 13 May). A 'Batavia' type crisp lettuce 'Estibaliz' was used in Fall and 'Venecia' in Spring. Lettuce plants were planted at a spacing of $0.3 \times 0.3 \mathrm{~m}$. along the whole greenhouse area.

Spraying was necessary twice at the beginning of each of the experiments conducted in Fall, 2002 and 2003 to control cutworms (Agrotis sp.) and other lepidopteran pests (e.g., Autographa gamma L.) which reached economically damaging levels. Insecticidal baits [clorpirifos 1\% (GB) p/p] and two Bacillus thuringiensis $24 \%$ (WP) p/p sprays were applied in both greenhouses to selectively control these lepidopteran pests and to avoid any detrimental effects on insect vectors of virus diseases. No pesticides were needed in the experiment conducted in Spring 2003.

Insect sampling methods. Each greenhouse was divided for statistical purposes into foursectors or quadrants (replications) of equal size during the experiment of 2002 and six sectors (replications) of equal size during the two experiments of 2003 for sampling purposes. Insect population dynamics were monitored in three different ways: sticky traps, horizontal water traps and visual counting. The relative population size of aphids, thrips, whiteflies and leafhoppers were estimated by sampling insects with yellow and blue sticky traps $(0.20$ $\times 0.25 \mathrm{~m})($ Biobest n.v., Westerlo, Belgium) placed in the centre of each sector of the greenhouse (four or six traps per greenhouse). Traps were replaced weekly during the whole lettuce growth cycle and the number of aphids, thrips, whiteflies and leafhoppers were counted in the laboratory.

A horizontal green tile trap (Irwin, 1980) was placed in the middle of each greenhouse to monitor landing rates of insects potentially acting as virus vectors (aphids, thrips, whiteflies and leafhoppers). Insects were collected from the traps at intervals of $15 \mathrm{~d}$ starting just after plant transplant.

At the same time, 15 plants per sector were randomly selected following a zig-zag pattern and visually inspected every 2 weeks as well as at harvest time to determine the presence or absence of insect pests colonizing lettuce plants. For aphids, a density scale was used to indicate the level of aphid infestation on the inspected plants, as follows: $0=$ no aphids, $<5$ $=$ plants infested with 1 to 4 aphids and $>5=$ plants infested with 5 or more aphids. This scale was used because 5 aphids/plant is the threshold value established for acceptance or rejection of the lettuce in the market.

Virus incidence. Lettuce plants were monitored at different time intervals by inspecting all plants within each greenhouse sector and taking leaf samples of plants showing symptoms of virus disease. Identification of viruses was conducted by enzyme-linked immunoabsorbent assay (ELISA)(Clark and Adams, 1977) using specific antibodies: lettuce mosaic virus (LMV) [Agdia(Elkart, IN), BiorebaAG(Switzerland), Loewe Biochemica GmbH(Germany)], broad bean wilt virus (BBWV) [Loewe Biochemica $\mathrm{GmbH}$ (Germany)], Alfalfa mosaic virus
A. Autumn, 2002

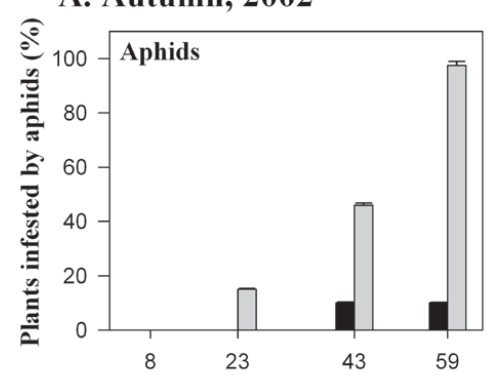

B. Spring, 2003

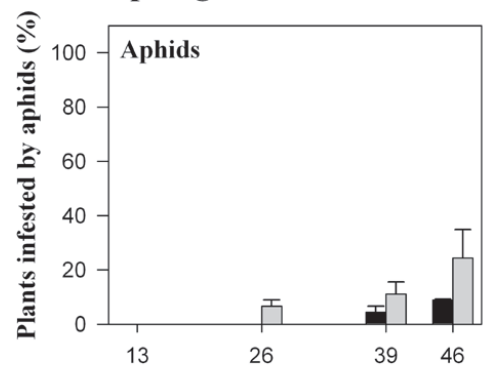

C. Autumn, 2003

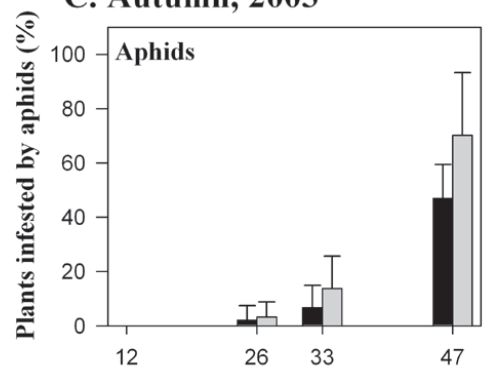

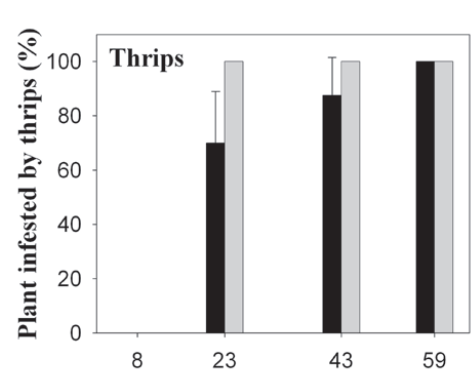

Days after transplanting
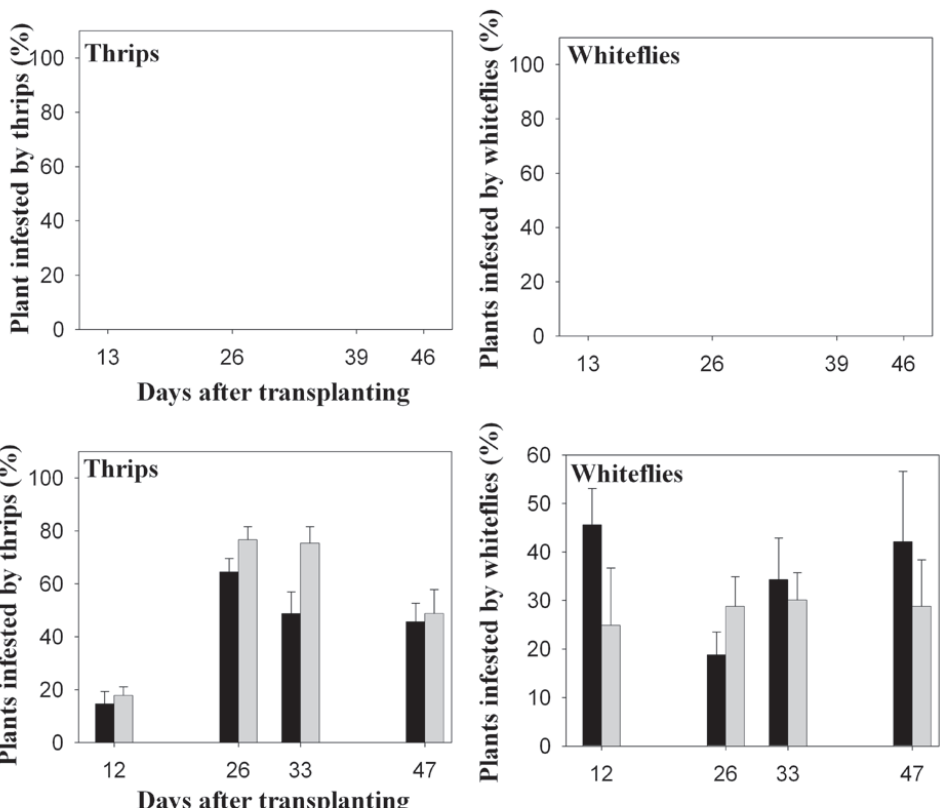

AD- IR AV film Astrolux film

Fig.1. Percentage of plants infested by insects in tunnels covered with UV-blocking film (AD-IR AV) and non-UV blocking film (Astrolux) during Fall 2002 and 2003 and Spring 2003 lettuce crops. Dates with no bars indicate that none of the plants were infested by insects. 
(AMV) [Loewe (Biochemica GmbH (Germany)], beet western yellow virus (BWYV), cucumber mosaic virus (CMV) [Agdia (Elkart, IN)] and tomato spotted wilt virus (TSWV) [Loewe Biochemica GmbH (Germany)] and a general anti-potyvirus monoclonal antibody [Agdia (Elkart, IN)] (Koening, 1981).

These specific antibodies were selected because the above-mentioned viruses were the ones that were most frequently found in a three-year survey recently conducted by our research group in the major lettuce-producing areas of Spain (Moreno et al., 2004).

In the experiment conducted in Fall, 2003 a sample of 24 randomly selected lettuce plants per tunnel (four plants per sector) was taken at harvest time to compare the impact of the two types of greenhouse film covers on the mean fresh weight $(\mathrm{g})$ per plant.

Statistical analysis. Data obtained from yellow and blue sticky traps, from the percentage of plants infested with each particular insect pest and from the yield of lettuce plants were subjected to a 1 -factor analysis of variance (ANOVA). Data from traps was previously transformed by $\ln (x+1)$ and data from plants was transformed by $\mathrm{x}=\arcsin \sqrt{\mathrm{x}}$ to reduce heterocedasticity.

When normality was not achieved after transformation, according to a Shapiro-Wilk test, non-gaussian variables were compared using a Mann-Whitney U test. In all cases, analysis of the data was conducted using SPSS 12.05 statistical package for Windows (SPSS Inc., 2003).

\section{Results}

Light transmission of plastic films. UV and visible light measured through the UV-blocking film (AD-IR AV) before any exposure to field conditions showed that this film was able to transmit only $1.9 \%$ of the total incident UV radiation $\left(2 \mu \mathrm{mol} \cdot \mathrm{m}^{-2} \cdot \mathrm{s}^{-2}\right)$ and $88.9 \%$ of the visible light spectrum $\left(1778 \mu \mathrm{mol} \cdot \mathrm{m}^{-2} \cdot \mathrm{s}^{-2}\right)$. At the same initial conditions, the non-UV blocking film (Astrolux) transmitted $15.4 \%$ of the total incident UV radiation $\left(16 \mu \mathrm{mol} \cdot \mathrm{m}^{-2} \cdot \mathrm{s}^{-2}\right)$ and $82 \%$ in the visible light spectrum $\left(1640 \mu \mathrm{mol} \cdot \mathrm{m}^{-2} \cdot \mathrm{s}^{-2}\right)$. After 14 month exposure to field conditions the UV-blocking film almost maintained its UV blocking properties and only $2.5 \%$ of the total incident UV-radiation was transmitted through the film $\left(2.6 \mu \mathrm{mol} \cdot \mathrm{m}^{-2} \cdot \mathrm{s}^{-2}\right)$. The ability to transmitradiation of the visible light spectrum by this same film was reduced to $83 \%$ (1641 $\mu \mathrm{mol} \cdot \mathrm{m}^{-2} \cdot \mathrm{s}^{-2}$ ) after 14 months of exposure to field conditions. The non-UV absorbing film (Astrolux) showed a similar trend, increasing its capacity to transmit UV light to $17.2 \%$ (18 $\left.\mu \mathrm{mol} \cdot \mathrm{m}^{-2} \cdot \mathrm{s}^{-2}\right)$ and reducing the visible light transmission to $70 \%\left(1395 \mu \mathrm{mol} \cdot \mathrm{m}^{-2} \cdot \mathrm{s}^{-2}\right)$.

Fall 2002 trial. The most abundant insect pests detected on lettuce plants were the aphid species, Macrosiphum euphorbiae (Thomas) and Acyrthosiphum lactucae (Passerini) followed by the western flower thrips, Frankliniella occidentalis (Pergande). The greenhouse whitefly, Trialeurodes vaporariorum (Westwood) was found on plants only on a specific sampling date: $23 \mathrm{~d}$ after transplanting. The percentage of lettuce plants colonized in the greenhouse whitefly that date was $22.5 \%$ and $2.5 \%$ under the greenhouse covered by the Astrolux and AD-IR AV plastic film, respectively (Fig. 1A).

Thrips colonized $100 \%$ of the lettuce plants sampled in the walk-in tunnel covered with the Astrolux film starting from the beginning of the lettuce growing cycle, whereas the percentage of plants colonized by thrips was significantly lower in the AD-IR AV film $23 \mathrm{~d}$ after transplanting but reached $100 \%$ at harvest time (Fig. 1A). The overall mean percentage of plants infested by thrips during the whole sampling period was significantly lower under the AD-IRAV than under the Astrolux film $(F=$ $7.59, \mathrm{df}=1,22, P=0.012$ ).

The UV blocking film caused a major reduction in aphid populations. At harvest
A. Autumn, 2002

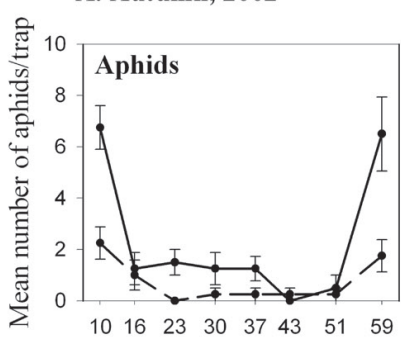

B. Spring, 2003

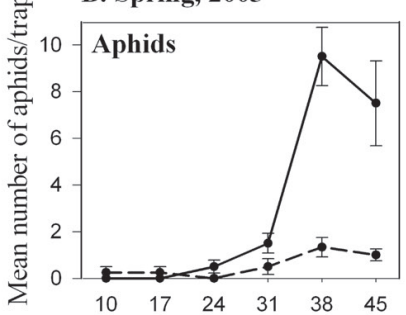

C. Autumn, 2003

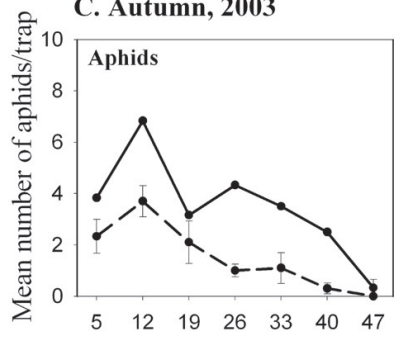

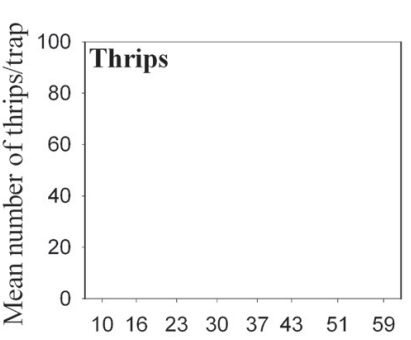

Days after transplanting

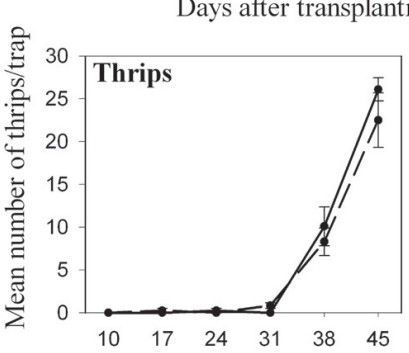

Days after transplanting

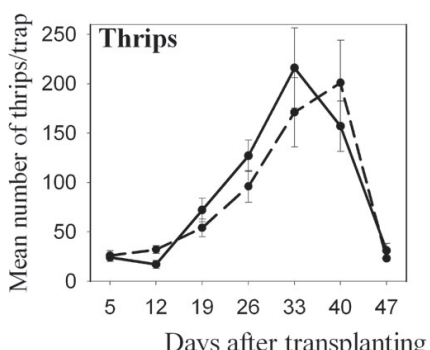

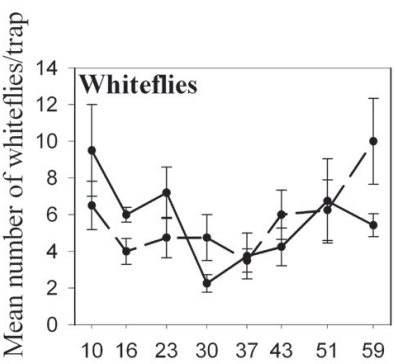
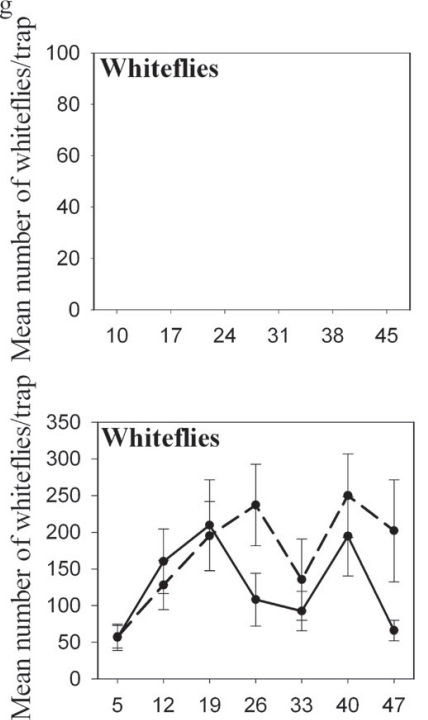

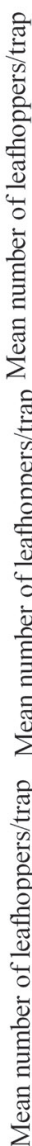

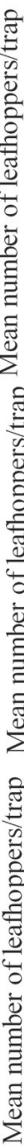

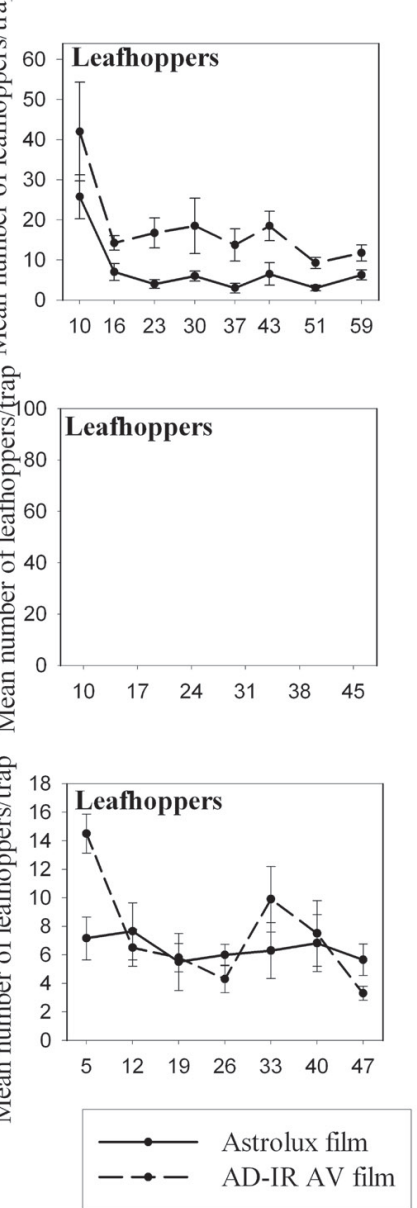

Fig. 2. Mean number of insects \pm SE captured on yellow sticky traps in tunnels covered with UV-blocking film (AD-IR AV) and non-UV blocking film (Astrolux) during fall and spring lettuce crops. Dates with no data indicate that no insects were caught by the traps. 
Table 1. Virus incidence in lettuce grown under the tunnel covered with UV-blocking film (AD-IR AV) and non-UV blocking film (Astrolux).

\begin{tabular}{|c|c|c|c|c|c|c|}
\hline \multirow{3}{*}{$\begin{array}{l}\text { Days after } \\
\text { transplanting }\end{array}$} & \multicolumn{6}{|c|}{ Viruses present ${ }^{z}$} \\
\hline & \multicolumn{3}{|c|}{ AD-IR AV film ${ }^{y}$} & \multicolumn{3}{|c|}{ Astrolux film ${ }^{x}$} \\
\hline & $\mathrm{N}^{\mathrm{w}}$ & $\mathrm{TSWV}^{\mathrm{v}}$ & Potyvirus & $\mathrm{N}^{\mathrm{w}}$ & $\mathrm{TSWV}^{\mathrm{v}}$ & Potyvirus \\
\hline \multicolumn{7}{|l|}{ Fall 2002} \\
\hline 10 & 40 & 4 & 11 & 36 & 1 & 6 \\
\hline 43 & 7 & 7 & 7 & 25 & 19 & 25 \\
\hline 58 & 3 & 1 & 3 & 80 & 19 & 64 \\
\hline Total & 50 & 12 & 21 & 141 & 39 & 95 \\
\hline \multicolumn{7}{|l|}{ Fall 2003} \\
\hline 12 & 6 & 1 & 2 & 7 & 1 & 4 \\
\hline 26 & 7 & 1 & 3 & 15 & 4 & 8 \\
\hline 47 & 5 & 0 & 1 & 8 & 2 & 6 \\
\hline Total & 18 & 2 & 6 & 30 & 7 & 18 \\
\hline
\end{tabular}

${ }^{2}$ Number of infected plants.

yUV-blocking plastic, AD-IR AV.

${ }^{x}$ Non-UV blocking plastic film, Astrolux.

"Number of plants analyzed by ELISA (all plants with virus-like symptoms were sampled).

vTomato spotted wild virus.

time, the percentage of lettuce plants infested by at least one aphid was $97.5 \%$ in the case of the greenhouse covered with Astrolux, but only $10 \%$ of the lettuce plants grown under the AD-IR AV film were infested with one or more aphids (Fig.1A). A higher percentage of plants with five or more aphids were found under the Astrolux film $(80 \% \pm 11.5 \%)$ than under the AD-IR AV film $(10.0 \% \pm 7.1 \%)$ at harvest time. Differences in the percentage of plants infested with five or more aphids were highly significant $(F=17.12, \mathrm{df}=1,22, P=$ 0.006 ) between the two treatments.

Fewer number of alate aphids were captured throughout the sampling period on yellow sticky traps located under the AD-IR AV film (overall mean $0.7 \pm 0.2$ ) than under the control Astrolux film (overall mean $2.4 \pm 0.5$ ) (Fig. 2A) showing significant differences between treatments $(U=334.5, P=0.011)$. However, no significant differences $(F=0.648 ; \mathrm{df}=1,62$, $P=0.424$ ) were obtained between the mean number of whiteflies captured on yellow traps located in the greenhouse covered with AD-IR AV film $(5.7 \pm 0.6)$ and those captured under the Astrolux film (5.4 0.6) (Fig. 2A).

The population level of leafhoppers, mainly Empoasca sp., was high at the beginning of the sampling period, and remained higher under the AD-IR AV than under the Astrolux film according to the yellow sticky trap captures (Fig. 2A). The overall mean number of leafhoppers trapped during the sampling period was significantly higher in the AD-IRAV treatment $(F=25.2, \mathrm{df}=1,62, P=0.0001)$.

Low numbers of insect vectors were caught on the blue sticky traps and in the horizontal green tile traps and therefore, the data was not suitable for statistical analysis.

Virus incidence was first assessed $10 \mathrm{~d}$ after transplant (19Sept.) and the only two groups of viruses detected during the survey were TSWV and Potyviruses (Table 1). Only symptomatic plants that were positive when tested by ELISA were regarded as being infected. Most of the Potyvirus-infected plants were identified as being infected with the LMV. There were clear significant differences between the number of infected plants under the AD-IR AV film and under the Astrolux film $43 \mathrm{~d}$ after transplant- ing (22 Oct.) (Table 1). At harvest time, the differences in virus incidence under each type of film were even more obvious.

The minimum and the mean air temperature recorded inside the tunnel covered by the $\mathrm{AD}$ IR AV film was generally higher than those recorded under the Astrolux film.

Spring 2003 trial. The most abundant insect pests colonizing lettuce plants were aphids, mainly $M$. euphorbiae, and also the silver Y moth, A. gamma.

The percentage of plants infested by aphids was always lower under the AD-IR AV than in the Astrolux tunnel. The mean percentage of plants infested by 1 or more aphid was $3.4 \% \pm 1.4 \%$ under the AD-IR AV and $11.5 \%$ $\pm 3.5 \%$ under the Astrolux tunnel, showing significant differences between treatments $(\mathrm{F}$ $=4.280, \mathrm{df}=1,42, P=0.045)$. The occurrence of $M$. euphorbiae in the tunnel covered with AD-IR AV film was detected 13 d later than in the tunnel covered with the Astrolux film (Fig. 1B). At harvest, the percentage of plants infested by aphids reached $8.9 \%$ in the tunnel covered with AD-IR AV while a total of 24.4 $\%$ plants were infested by aphids under the Astrolux film (Fig. 1B).

Larvae of A. gamma reached damaging levels close to harvest time. The percentage of lettuce plants infested by $A$. gamma was significantly lower under the AD-IRAV film $(17.8 \% \pm 4.1 \%)$ than under the Astrolux film $(37.8 \% \pm 5.6 \%)(F=$ $8.63, \mathrm{df}=1,10, P=0.015)$. The mean number of larvae per plant was also significantly lower under the AD-IR AV tunnel $(0.19 \pm 0.04)$ than under the Astrolux tunnel $(F=9.49, \mathrm{df}=1,10$, $P=0.002)$

The mean number of alate aphids captured on yellow sticky traps under the AD-IR AV film $(0.6 \pm 0.1)$ was significantly lower than under the Astrolux film $(3.8 \pm 0.8)(F=13.59$, $\mathrm{df}=1,10, P=0.001$ ) (Fig. 2B). However, no differences were obtained between the number of thrips caught on yellow sticky traps under the two types of plastic films $(F=0.603, \mathrm{df}=$ $1,10, P=0.402$ ) (Fig. 2B). A similar trend was observed in the number of thrips captured on blue sticky traps during the whole sampling period under the AD-IR AV film $(16.2 \pm 3.6)$ and the Astrolux film $(21.1 \pm 8.6)$, showing no significant differences between treatments ( $\mathrm{F}$ $=0.16$, $\mathrm{df}=1,42, P=0.899$ ).

A very low number of insect vectors were captured in the horizontal green tile traps and no plants with virus symptoms were detected in the UV-blocking tunnel. In the non-UV blocking tunnel only eight plants were infected by potyviruses at harvest time (13 May).

During the Spring 2003 trial the maximum and minimum temperatures were rather similar under both types of covers.

Fall 2003 trial. The most abundant pest species detected on lettuce plants were aphids (M. euphorbiae and A. lactucae), the western flower thrips, F. occidentalis and the greenhouse whitefly, $T$. vaporariorum.

At harvest time, the percentage of plants colonized by at least one aphid was $47 \% \pm$ $12.5 \%$ under the AD-IR AV tunnel and $70.2 \%$ $\pm 23.1 \%$ under the Astrolux tunnel (Fig. 1C). Also, a significantly lower percentage of plants infested by $\geq 5$ aphids were detected in the AD-IR AV tunnel $(16.7 \% \pm 2.2 \%)$ than in the Astrolux tunnel $(43.5 \% \pm 10.5 \%)$ at harvest time $(F=6.555, \mathrm{df}=1.10, P=0.028)$. Population of aphids captured on yellow sticky traps were always low in both tunnels but significantly higher in the tunnel covered with the Astrolux film $(3.5 \pm 0.4)$ than in the tunnel covered with the AD-IR AV film (1.5 \pm 0.26 ), showing significant differences between treatments over the whole the sampling period $(\mathrm{U}=4.41, P=0.0001)$ (Fig. $2 \mathrm{C})$.

Thrips population density detected on plants was lower under the AD-IR AV film than the Astrolux film (Fig. 1C). The percentage of plants infested by thrips for the whole sampling period was $43.4 \% \pm 4.2 \%$ and $54.6 \% \pm 5.8 \%$ under the AD-IR AV and the Astrolux film, respectively. No significant differences were found between treatments during the sampling period $(F=2.47, \mathrm{df}=1,46, P=0.122)$. The thrips population curve caught on yellow sticky traps showed similar trends under both types of plastic films during the lettuce growth cycle (Fig. 2C). The mean number of thrips caught inside the AD-IR AV and the Astrolux tunnel was $92.1 \pm 13.1$ and $85.9 \pm 13.2$, respectively, showing no significant difference between treatments $(\mathrm{F}=0.002, \mathrm{df}=1,82, \mathrm{P}=0.962)$.

Also, the mean number of thrips caught on blue sticky traps was $152.6 \pm 21.6$ and $163.0 \pm$ 24.5 under the AD-IR AV film and under the Astrolux film, respectively. No significant differences were found between the two tunnels during the sampling period $(\mathrm{F}=0.056, \mathrm{df}=$ $1,82, P=0.814)$.

The percentage of plants infested by at least one whitefly was higher under the ADIR AV than the Astrolux film on most of the dates sampled (Fig. 1C). The mean number of infested plants was similar under both types of plastic films (overall mean was $35.2 \% \pm$ $4.9 \%$ under the Astrolux film and $36.1 \% \pm$ $4.7 \%$ under the AD-IR AV film), showing no differences between treatments $(F=0.009, \mathrm{df}$ $=1,46, P=0.015$ ).

Whitefly population density caught on yellow sticky traps was on occasions higher in the tunnel covered with UV-blocking film than in the one with the Astrolux film (Fig. 2C). The 
mean number of whiteflies per trap caught on yellow sticky cards over the whole sampling period was $172.2 \pm 19.0$ under the AD-IRAV film and $126.6 \pm 16.6$ under the Astrolux film. The mean population density of whiteflies captured on sticky traps showed significant differences over the whole trial between both treatments $(F=5.28, \mathrm{df}=1,62, P=0.024)$.

The leafhopper population curve fluctuated during the sampling period between six to eight insects per trap in the Astrolux tunnel, whereas, the population density in the AD-IR AV tunnel was higher 5 days after transplanting but remained low during most of the sampling period (Fig. 2C).

Potyviruses and TSWV were the only two viruses detected by ELISA on the lettuce plant samples collected during the Fall 2003 trial. The number of infected plants was always higher in the Astrolux than in the AD-IRAV tunnel(Table 1), the same as in the Fall 2002 trial.

Maximum and minimum temperature was steadily higher in the AD-IR AV tunnel than in the Astrolux tunnel. Consequently, lettuce plants grown under the UV-blocking film showed more precocity and larger size. The mean fresh weight per plant of the lettuce grown under the Astrolux film $(445.4 \pm 24.7 \mathrm{~g})$ was significantly lower than the yield obtained under the AD-IR AV film $(612.5 \pm 26.8 \mathrm{~g})$ and such differences were highly significant $(F=$ 21.01, df $=1,46, P=0.0001)$.

\section{Discussion}

The UV-absorbing plastic film, AD-IR AV maintained their property to filter UV radiation, reducing its capacity to block UV radiation up to only $0.6 \%$ after 14 months of field exposure.

The UV-absorbing plastic film effectively reduced immigration, population density and spread of the aphid species (M. euphorbiae and A. lactucae) found inside the tunnel covered with the UV-absorbing plastic film. The lower immigration rate of aphids inside the tunnel covered with UV-blocking film was determined by a lower catch of these insects on the yellow sticky traps compared to the control Astrolux tunnel on all of the three trials tested. In Fall 2003, the aphids entered both tunnels at the same time, however, in Fall 2002 and in the Spring 2003 season the first aphid detected on plants was delayed about $15 \mathrm{~d}$ in the greenhouse covered with the UV-blocking plastic film.

Probably, the low UV radiation present in the AD-IR AV tunnel reduced the landing rate and the movement of aphids across lettuce plants, and in consequence a lower percentage of plants became infested by aphids. Furthermore, the significant reduction obtained in the number of plants infected with aphid-transmitted viruses (potyviruses) in the UV-deficient environment also suggests that aphid movement was impaired under the AD-IR AV tunnel. These results are in agreement with those reported by Antignus et al. (1996) who found a strong reduction in the number of cotton aphids, Aphis gossypii trapped on yellow sticky traps located under a UV-absorbing film.
No alate aphids were captured by the green tile traps, although yellow sticky traps were always capable of capturing some aphids. This result probably reflects that the horizontal green tile trap has a spectral reflectance and a horizontal position in the canopy able to capture absolute landing rates closest to actual landing of aphids on the crop (Irwin, 1980, Boiteau, 1990) and therefore, failed to capture aphids flying at low heights from short distances inside the tunnel. Furthermore, the yellow color of sticky traps is generally more attractive than green to many aphid species (Eastop, 1955). It is well known that there is not always a good correlation between the number of insects captured by traps and the level of infestation (density) found on plants (Robert et al., 1988). Therefore, it is important to use more than one sampling technique to assess the real level of aphid infestation.

The UV-blocking film was able to increase the number of marketable plants when the threshold level was established on five or more aphids per plant and the size of aphid colonies present on infested plants was always lower under the UV-blocking film. This result suggests that the reproduction rate of $M$. euphorbiae was reduced as described for $M$. persicae under a UV-blocking film (Chyzik et al. 2003), although this assumption needs further investigation.

Frankliniella occidentalis infested a higher percentage of lettuce plants in Fall 2002 whereas no significant differences were found in the number of infested plants between the UV- blocking and the control treatment in the Fall 2003 trial. However, the incidence of TSWV was always lower under the tunnel covered with UV-blocking film in the two trials conducted in Fall. This reduction in the incidence of the virus also suggests a reduction in the vector activity of thrips under UV-deficient environments.

In our study, the UV-blocking film showed no positive effect against the greenhouse whitefly $T$. vaporariorum. This whitefly species was captured on yellow sticky traps only in the Fall growing seasons under both types of films although population density was much higher in 2003.

In our study we caught on yellow sticky traps a higher number of whiteflies in the tunnel covered with UV-blocking film than in the control tunnel in the trial of 2003 although no significant differences were obtained in the 2002 trial. Also, we found no significant differences in the percentage of plants infested by at least 1 whitefly under both types of films. Our results are consistent with those reported by Costa et al. (2002) that found no reduction in the population density on plants nor in sticky trap catches of $T$. vaporariorum in commercial greenhouses with open sides covered by a plastic film that blocked UV light at wavelengths of $380 \mathrm{~nm}$ and below compared with a film that blocked UV light at wavelengths of 360 $\mathrm{nm}$ and below. In contrast, Doukas (2001) and Mutwiwa et al. (2005) obtained a significant reduction in the immigration and dispersion of $T$. vaporariorum enclosed tunnels covered with UV-blocking plastic films. These striking differences between the results obtained by the different studies conducted to analyze the effects of UV-blocking films on T. vaporariorum are probably due to the large differences in the level of UV light present in the regions where these studies were conducted. Our present study and the one reported by Costa et al (2002) were conducted in Spain and California with high levels of UV radiation, whereas the one reported by Doukas (2001) and Mutwiwa et al. (2005) were carried out in United Kingdom and Germany (latitude $52^{\circ} \mathrm{N}$ ), respectively under poor UV light conditions. Furthermore, the two latter studies were conducted under complete enclosed tunnels without open sides possibly resulting in differences in the UV intensity present inside the tunnels used for the different studies referred above.

The impact of the UV-blocking film on the leafhoppers populations was not clear, because in Fall 2002 more leafhoppers were trapped on yellow traps inside the tunnel protected with UV-blocking film, but no similar trend was found in the Fall 2003 trial. A possible explanation for the Fall 2002 result is the presence of high densities of leafhoppers that were present in maize fields located in the vicinity of the greenhouse covered with UVblocking films.

The UV-blocking film was able to reduce the population density and the percentage of plants infested by larvae of A. gamma, indicating a possible effect of the film on the orientation and host-finding ability of adult moths of this species under poor UV light environments.

Furthermore, the UV-blocking plastic film was able to modify environmental conditions inside the tunnel, increasing air temperature, especially in the Fall grown-lettuce. Consequently, an increase in precocity of lettuce plants was observed under the UV-absorbing film.

Our results showed that the UV-blocking film tested acts as an effective control strategy against aphids and a lepidoptera pests and a partial control of thrips. In addition, the incidence and spread of insect-transmitted virus diseases infecting lettuce was significantly reduced under the UV-plastic films. To enhance the efficacy of UV-blocking film to control insect pests it is important to select and adequate type of UV-blocking plastic film (Antignus etal., 1996), to improve the design of the greenhouse because this may significantly affect the amount of filtered light entering the system (Costa et al., 2002), and to develop a good management strategy of insects occurring in the surrounding crops and reservoirs which may act as sources of new immigrants entering the protected crop.

\section{Literature cited}

Antignus, Y., N. Mor, R.B. Joseph, M. Lapidot, and S. Cohen. 1996. Ultraviolet-absorbing plastic sheets protect crops from insect pests and from virus diseases vectored by insects. Environ. Entomol. 25:919-924.

Antignus, Y., M. Lapidot, D. Hadar, Y. Messika, and S. Cohen. 1998. Ultraviolet-absorbing screens serve as optical barriers to protect crops from virus and insect pests. J. Econ. Entomol. 


$$
\text { 91:1401-1405. }
$$

Antignus, Y. 2000. Manipulation of wavelength dependent behavior of insects an IPM tool to impede insects and insect-borne virus. Virus Res. 71:213-220.

Antignus, Y., D. Nestel, S. Cohen, and M. Lapidot. 2001. Ultraviolet-deficient greenhouse environment affects whitefly attraction and flight-behavior. Environ. Entomol. 30:394-399.

Antignus, Y. and D. Ben-Yakir. 2004. Ultravioletabsorbing barriers, an efficient integrated pest management tool to protect greenhouses from insects and virus diseases, p. 319-335. In: A.R. Horowitz and I. Ishaaya (eds.). Insect pest management. Springer-Verlag, Berlin.

Boiteau, G. 1990. Effect of trap color and size on relative efficiency of water-pan traps for sampling alate aphids (Homoptera: Aphididae) on potato. J. Econ. Entomol. 83:937-942.

Boiteau, G. 2002. Physical barriers for the control of insect pests, p. 616-618. In: D. Pimentel (ed.). Encyclopedia of pest management. Marcel Dekker, Inc., New York.

Costa, H.S. and K.L. Robb. 1999. Effects of ultraviolet-absorbing greenhouse plastic films on flight behavior of Bemisia argentifolii (Homoptera: Aleyrodidae) and Frankliniella occidentalis
(Thysanoptera: Thripidae). J. Econ. Entomol. 92:557-562.

Costa, H.S., K.L. Robb, and C.A. Wilen. 2001. Increased persistence of Beauveria bassiana spore viability under high ultraviolet-blocking greenhouse plastic. HortScience 36:1082-1084.

Costa, H.S., K.L. Robb, and C.A. Wilen. 2002. Field trials measuring the effects of ultraviolet-absorbing greenhouse plastic films on insect populations. J. Econ. Entomol. 95:113-120.

Clark, M.F. and A.N. Adams.1977. Characteristics of the microplate method of enzyme-linked inmunoabsorbent assay for the detection of plant viruses. J. Gen. Virol. 34:475-483.

Chyzik, R., S. Dobrinin, and Y.Antignus. 2003. Effect of a UV-deficient environment on the biology and flight activity of Myzus persicae and its hymenopterous parasite Aphidius matricariae. Phytoparasitica 31:467-477.

Eastop, V.F. 1955. Selection of aphid species by different kinds of insect traps. Nature. 176:936.

Doukas, D.E. 2001. Impact of spectral cladding materials on the behavior of glasshouse whitefly Trialeurodes vaporariourum and Encarsia Formosa, its Hymenopteran parasitoid. MSc. thesis. Univ. Reading, U.K.

Irwin, M.E. 1980. Sampling aphids in soybean fields, p. 239-259. In: M. Kogan and D.C. Herzog (eds.). Sampling methods in soybean entomology. Springer-Verlag, New York.

Koening, R. 1981. Indirect ELISA methods for the broad specificity detection of plant viruses. J. Gen. Virol. 55:53-62.

Moreno, A., C. De Blas, R. Biurrun, M. Nebreda, I. Palacios, M. Duque, and A. Fereres. 2004. The incidence and distribution of viruses infecting lettuce, cultivated Brassica and associated natural vegetation in Spain. Ann. Appl. Entomol. 144(3):339-364.

Mutwiwa, U.N., C. Borgemeister, B. Von Elsner, and H.J. Tantau. 2005. Effects of UV-absorbing plastic films on greenhouse whitefly (Homoptera: Aleyrodidae). J. Econ. Entomol. 98:1221-1228.

Raviv, M. and Y. Antignus. 2004. UV radiation effects on pathogens and insect pests of greenhouse-grown crops. Photochem. Photobiol. 79:219-226.

Robert, Y, C.A. Dedryver, and J.S. Pierre. 1988. Sampling techniques, p. 1-20. In: A.K. Minks and P. Harrewijn (eds.). Aphids their biology, natural enemies and control, vol. C. Elsevier, Amsterdam.

SPSS. 2003. SPSS statistical package, version 12.05, Chicago, SPSS Inc. 